\title{
Artificial Intelligence and Medical Negligence in Malaysia: Confronting the Informed Consent Dilemma
}

Hartini Saripan, Nurus Sakinatul Fikriah Mohd Shith Putera, Rafizah Abu Hassan, Sarah Munirah Abdullah

To Link this Article: http://dx.doi.org/10.6007/IJARBSS/v11-i11/11254

DOI:10.6007/IJARBSS/v11-i11/11254

Received: 07 September 2021, Revised: 30 September 2021, Accepted: 14 October 2021

Published Online: 02 November 2021

In-Text Citation: (Saripan et al., 2021)

To Cite this Article: Saripan, H., Putera, N. S. F. M. S., Hassan, R. A., \& Abdullah, S. M. (2021). Artificial Intelligence and Medical Negligence in Malaysia: Confronting the Informed Consent Dilemma. International Journal of Academic Research in Business and Social Sciences, 11(11), 293 - 302.

Copyright: (c) 2021 The Author(s)

Published by Human Resource Management Academic Research Society (www.hrmars.com)

This article is published under the Creative Commons Attribution (CC BY 4.0) license. Anyone may reproduce, distribute, translate and create derivative works of this article (for both commercial and non-commercial purposes), subject to full attribution to the original publication and authors. The full terms of this license may be seen at: http://creativecommons.org/licences/by/4.0/legalcode

Vol. 11, No. 11, 2021, Pg. $293-302$

Full Terms \& Conditions of access and use can be found at http://hrmars.com/index.php/pages/detail/publication-ethics 


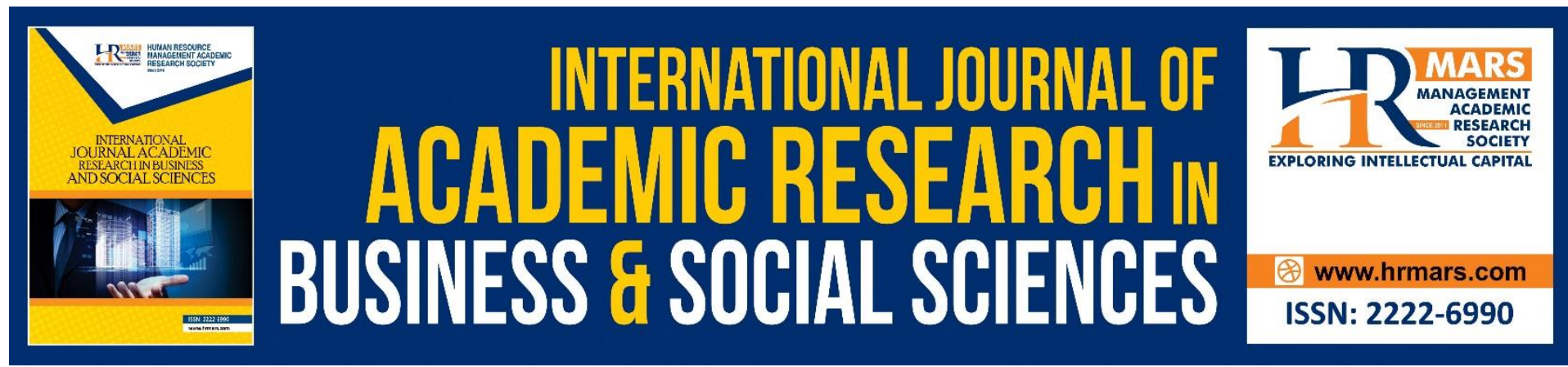

\title{
Artificial Intelligence and Medical Negligence in Malaysia: Confronting the Informed Consent Dilemma
}

\author{
Hartini Saripan, Nurus Sakinatul Fikriah Mohd Shith Putera, \\ Rafizah Abu Hassan, Sarah Munirah Abdullah \\ Faculty of Law, Universiti Teknologi MARA, 40450 Shah Alam, Malaysia
}

\section{Abstract}

Artificial Intelligence (AI) is poised to contribute significant impacts in medical diagnostic and decision making by enabling unparalleled performance leaps. The integration of Al to medical diagnosis and decision-making process potentially scales down the number of medical errors and misdiagnoses - and allow diagnosis based on unidentified, black-boxed interpretations of data. However, by transferring parts of the decision-making role to an algorithm, increased reliance on Al impedes potential malpractice claims when doctors pursue erroneous treatment based on algorithmic recommendations. With more controversial errors surrounding the technology is in the offing, the conventional requirement of informed consent underpinning the operation of medical malpractice is a bottleneck. As Al proliferates in healthcare, new ethical and practical problems concerning informed consent surged. These problems have been the motivation behind this research whereby the use of $\mathrm{Al}$, particularly in determining the course of treatment or procedures for patients, invites such concerns over the informed consent requirement. Indeed, these are novel challenges that surrounds the adoption of Al in the healthcare domain which is vital to be addressed. Therefore, this research investigates how Al intersects with the concept of informed consent and proceed to determine to what extent Al's involvement in a patient's health should be disclosed under the current doctrine. Combining doctrinal analysis and a case study approach, this research explores legal propositions through the reasoning of statutory provisions, related case law and reports of medical malpractice claims addressing the potential treatment error given at the suggestion of an Al system. The research has contributed in expanding the requirement of informed consent in light of the use of Al for clinical decision making. This outcome is significant in shaping the transparency and trustworthiness in the governance of Al in healthcare. Such contribution is ultimately in tandem with the Strategic Thrust 2 of the Shared Prosperity Vision 2030 initiated by the Ministry of Economic Affairs in restructuring the priorities of Malaysia's development. This is aimed at revolutionising the healthcare ecosystem through transformative technologies and comprehensive ICT solutions outlined in the Key Economic Growth Activities (KEGA) 14, which includes Al as advanced and modern services. An operative malpractice liability framework is paramount in providing incentives for policing accurate diagnosis and treatment decisions for patients, all whilst savouring the benefits of disruptive medical technologies like Al. 
Keywords: Artificial Intelligence in Healthcare, Artificial Intelligence and Medical Negligence, Artificial Intelligence and Informed Consent

\section{Introduction}

Evidently, we are living in the age of intelligent machines. Artificial Intelligence (AI) has infiltrated our lives in previously unfathomable ways, performing tasks that could only be accomplished by a human with specialised expertise, costly training, or a government-issued licence. Healthcare has been seen as an early domain to be transformed by Al technology, alongside other significant fields such as transportation, energy, and military (Coiera, 2018). Many specialised healthcare applications, including (but not limited to) medical diagnostics, patient monitoring, and learning healthcare systems, are currently being developed or implemented using Al software platforms (Price, 2019). As Al has established itself as a disruptive force in the healthcare industry, more recent breakthroughs are evident in the sector (Carfagno, 2019). For instance, Google researchers have collaborated with Northwestern Medicine to develop an Al system that can diagnose lung cancer with more precision than human radiologists (Birenbaum, 2019). This system, which analyses computed tomography (CT) scans to estimate one's likelihood of having the disease, was trained using a deep-learning algorithm. Further, researchers recently created an Al classifier that uses a wearable wrist biosensor to detect a specific cardiovascular illness. Hypertrophic cardiomyopathy is a disorder that can have catastrophic consequences and is frequently misdiagnosed in clinical settings. The medical industry has joined hand in taking a further step of embracing $\mathrm{Al}$ as the American Medical Association's (AMA) Current Procedural Terminology (CPT) Editorial Panel accepted a new category $1 \mathrm{CPT}^{\circledR}$ code for automated pointof-care retinal imaging, according to IDx, a privately held Al diagnostics company (American Medical Association, 2020). This new code, developed in collaboration with IDx and submitted by the American Academy of Ophthalmology (AAO), makes it easier to charge for IDx-DR, an FDA-cleared autonomous Al system that identifies diabetic retinopathy, a primary cause of blindness. This research, however, is dedicated to Al algorithms and software that are being developed to aid clinical decision-making and/or public health policymaking. These $\mathrm{Al}$ algorithms often use computerised predictive analytic algorithms to filter, organise, and search for trends in large data sets from a variety of sources, as well as provide a probability analysis that allows healthcare providers to make quick and informed judgments. Al's contribution to the healthcare industry is revolutionary, but not without a price. Now, imagine a hypothetical scenario as follows:

Tadashee developed a harsh, productive cough together with severe pain in his right chest that intensifies with inspiration. He then went to 6Hero Hospital to seek for treatment. 6Hero Hospital, an early adopter of advanced medical technologies, decided to use BayXam, an Al diagnostic tool instead of radiologists to interpret chest $x$-ray images as a way to reduce labour costs and increase efficiency. Following a chest $x$-ray view delegated by the attending physician to BayXam, Tadashee was prescribed with prednisolone, a steroid medication to abate his cough and breathing problem. During the 5 days of treatment, Tadashee's condition worsened, and he was rushed to the hospital. It was later identified that for unknown reasons, BayXam missed an obvious pneumonia causing Tadashee to suffer from septic shock. After further investigations, it was discovered that BayXam's misdiagnosis results from discrepancies between the data used to train BayXam and the real-world clinical scenario due to limited availability of 
high-quality training data at 6Hero Hospital. Al systems are not as equipped as humans to recognize when there is a relevant change in context or data that can impact the validity of learned predictive assumptions. Therefore, Al systems may unknowingly apply programmed methodology for assessment inappropriately, resulting in error.

Assuming that Tadashee's has been briefed with the use of BayXam as an aid to the attending physician, can he sue the attending physician under medical negligence for the misdiagnosis? In this setting, a physician bears various obligations to his patients, and it is expected that the practitioner will bring a reasonable degree of skill and knowledge to reinforce in exercising a reasonable degree of caution (Pandit \& Pandit, 2009). A medical practitioner owes a duty of care in deciding whether to take on a case or not, determining what treatment to give, administering the planned therapy, and refraining from performing any procedure beyond his or her control (Yadav et al., 2020). In light of Tadashee's scenario above, the situation concerns a physician's responsibility to give the patient information about a particular treatment or procedure so the patient can decide whether to undergo the treatment, procedure, or test. This process of providing essential information to the patient and getting the patient's agreement to a certain medical procedure or treatment is called informed consent. As the healthcare industry leverages on the combination of enormous datasets with predictive algorithms like Al to glean and recognise patterns of complex medical data, considerable legal questions are being raised around its deployment, one of them being end-user consent. What is the minimum par of technological information that must be disclosed to patients? What are the most effective ways to communicate the intricacies of $\mathrm{Al}$ system in a way that is understandable by the patient? All in all, what to tell the patient? These questions have ultimately been the motivation behind this research whereby the use of $\mathrm{Al}$, particularly in determining the course of treatment or procedures for patients, invites such concerns over the conventional requirement of informed consent. Indeed, these are novel challenges that surrounds the adoption of Al in the healthcare domain which is vital to be addressed.

\section{Informed Consent in the Artificial Intelligence Era}

Al is intended or developed to act in ways that are regarded to be 'creative' and "outside-the-box," but such actions may bring harm to users (or others), as the extent to which the machine would act autonomously may be unknown to the designers. It is worsened by the fact that most Al programmes are 'black boxes,' with the consumer unable to determine if the data used to train them is fair or representative, (Europäisches Parlament, 2020) as Al system functions on a basis other than total explainability is incapable of providing entire justifications for the verdicts and decisions it advises (Wadden, 2021). This means that the computation that resulted in the generated answer is unknown to the consumer, which is frequently the case since the method is protected by trade secrets or, worse, is undisclosed to the programmers because the Al-enabled device has acted on data that they are ignorant of or has established its own algorithms to "solve problems" without their knowledge (Giuffrida et al., 2018). In the same spectrum, it is within the duty of the physician to alert the patient of the system's risks. Before performing diagnostic tests or initiating medical treatments, the physician is required to get the patient's informed consent (Puteri Nemei, 2002). Regardless of a person's refusal on receiving information, this principle does not diminish the health care provider's obligation (or the client's right). The attending physician owes an obligation to tell the patient about the potential risks and to ensure that the patient 
grants consent prior to treatment and that such consent is informed. As derived from the case of Gurmit Kaur a/p Jaswant Singh v Tung Shin Hospital \& Anor, simply signing a consent document without ensuring the patient knows the risk is insufficient as such consent may be interpreted as a lack of informed consent. A botched consent process carries a major ethical and legal consequence. The goal is to make the patient feel informed and competent about the information that they are receiving. The failure of a physician to provide adequate information to the patient about a particular treatment is interpreted by the courts as a breach of duty by the physician (Koong et al., 2021). The implications of Al on the prevailing informed consent doctrine can be analysed through the cases involving its predecessor technology which is the robotic surgical system. In this context, the manufacturer of the cybersurgical robotic instrument must adequately warn patients of the instrument's potential hazard, properly design the device, and properly construct the instrument as in Da Vinci Robotic Surgical System (Barfield, 2018) (Matsuzaki, 2018)(Cohen, 2020)(Peyrou et al., 2019)(Allain, 2013).

The Da Vinci System is a robotic surgery system that doctors use to perform a variety of treatments. In contrast to conventional open surgery, the treatment can be performed remotely via small incisions. In the case of Taylor $v$ Intuitive Surgical, Intuitive Surgical (ISI) provided physicians with an instruction manual that contained multiple warnings about the device. Throughout their training, ISI advised surgeons not to perform prostatectomies on obese patients. Additionally, they prohibit physicians from doing treatments on patients who have already undergone lower abdomen surgery. Finally, ISI cautioned against the patient being in a steep Trendelenburg posture (head inclined downward) during the procedure. After obtaining informed consent, Dr. Ralf Bildsten, a urologist, operated on Taylor, who had a BMI of 39, which ISI considered to be significantly obese and contradicts ISI's advice that patients have a BMI of less than 30. Additionally, Taylor had three prior lower abdominal surgeries, contradicting ISI's recommendation that patients with past lower abdominal procedures are to be excluded. In this case, Dr. Bildsten was unable to position Taylor properly due to his weight, subsequently moved to open surgery and had the tear repaired by another surgeon. Taylor was unable to urinate due to certain circumstances and was wearing a colostomy bag. Subsequently, he was unable to walk without assistance. ISI, as the defendant, was liable for a set of allegations. The court determined that ISI was compelled to notify hospitals of the dangers associated with its surgical system. While the court focused on the manufacturer in this case, it is evident that the court recognised the physician's obligation to advise patients about the Da Vinci system before deploying it. Taking from the perspective of Al medical, the attending physician's conflict of interest in informing patients about potential risks appears to be inherent in the nature of Al. Due to the Al system's opacity, it might be difficult for health care practitioners to explain how it reached a judgement or made an error, and other difficulties may also arise, such as whether clinicians will have access to data on the Al system's predicted accuracy and mistake rates among patient categories, or whether the physicians can justify the system's forecast or decision (Cohen, 2020). The independent nature of Al may introduce issues of predictability and control, rendering ex-post regulation futile, particularly if an Al poses a catastrophic risk. It is unknown to what extent Al will behave autonomously. As a result, question arises as to the extent of which the attending physician is required to notify the patient of the danger of $\mathrm{Al}$, either generic information will be sufficient to fulfil the physician's obligation to warn the patient about the risk, or the patient must be informed of every bit of technological information that the system is equipped with. 
Despite the fact that the issue is complicated, the attending physician retains the responsibility to warn the patient about the risks of $\mathrm{Al}$.

\section{The Duty of Disclosure involving Artificial Intelligence - How Adequate is Adequate?}

The duty of disclosure has been increased and enforced, as part of the patient's right to obtain suitable and sufficient information prior to any medical treatment or procedure (Esham, 2019) However, in cases involving Al, it is undeniable that if the doctor thoroughly describes the various options to the patient including the use of the Al system, the patient may be confused given the different treatment strategies (Matsuzaki, 2018). Numerous studies have demonstrated the failure of the informed consent doctrine merely due to the difficulties in explaining complex data to patients in an effective manner (Cohen, 2020). When the duty to disclose is concerned, the Malaysian judges currently adopt the principle derived from Rogers $v$ Whitaker. The duty includes when a reasonable person in the patient's position would be likely to attach significance to it, and when such risks were material risks. The Federal Court judge held in Dr Hari Krishnan \& Anor v Megat Noor Ishak bin Megat Ibrahim \& Anor that if such information deprived the plaintiff of the chance to make an informed decision as to whether to proceed with the operation or otherwise, the medical practitioner has breached their duty. Such approach acknowledges the differing perspectives of each patient, not as just a reasonable man but a reasonable man in the patient's position (Esham, 2019). Such advice, cautions, information, options, explanations, or instructions are required to be communicated properly based on the medical organization's or practitioner's current practise, as ruled by the court in Mohd Fadli bin Bakar v Pengarah Hospital Hospital Seberang Jaya \& Or. This is to ensure that sufficient information was provided to prevent the physician from acting negligently and to safeguard the patient's right to autonomy, as referred by the learned High Court judge in Gurisha Taranjeet Kaur \& Anor v Dr Premitha Damodaran \& Anor. According to the case analysis, it is considered as adequate information when there was no medical evidence presented to establish that the physician's information and advice to the patient was inadequate and insufficient (the case quoted the ruling in Hong Chuan Lay v Dr Eddie Soo Fook Mun). A patient is withheld to complain about lack of information unless the patient requested additional information, or unless there is a special danger that must be disclosed to the patient in order for him to decide whether to submit to the operation or not (as referred by the Appellate Court in Hasan bin Datolah v Kerajaan Malaysia). Apart from the case law analysis, it is outlined in the Malaysian Medical Council Guideline on the necessity to warn material risks, the medical practitioner must inform the patient, in a way the patient understands, about the condition, investigation options, treatment options, benefits, all material risks, potential adverse effects or complications, residual effects, if any. No. 3 of Malaysian Medical Council Guideline states that:

"Relevant information includes disclosure of possible risks which the patient ought to know and/or should know. The medical practitioner must inform the patient, in a manner that the patient can understand, about the condition, investigation options, treatment options, benefits, all material risks, possible adverse effects or complications, the residual effects, if any, and the likely result if treatment is not undertaken, to enable the patient to make his own decision whether to undergo the proposed procedure, examination, surgery, or treatment."(MOH, 2016) 
Further, according to guideline No. 4, it has been highlighted on the explanatory notes and documents that it is recommended for practitioners to include extra information on the risks and side effects of any procedure in a written explanatory statement that the patient (or next-of-kin or legal guardian) can read, comprehend, and sign ( $\mathrm{MOH}, 2016)$. This is because in certain cases, the physician may need to disclose the risks to the patient's next of kin, who can ensure the patient's autonomy is protected (AMIRTHALINGAM, 2015). Additionally, for matters relating to prepared materials with information about a treatment, it has been prescribed in guideline No.14 that the physician should assist the patient in comprehending the information presented to them and the patient should be informed of any issues they may have about the information $(\mathrm{MOH}, 2016)$ Further, if such pre-prepared information material does not adequately reveal all "material hazards," either in general or in specific terms, the medical practitioner must verbally provide supplemental information on such "material risks." The greater the likelihood of a risk, the more precise the facts should be $(\mathrm{MOH}$, 2016). However, machine learning algorithms are becoming increasingly incomprehensible, which raises concerns about their autonomy and decision-making capabilities (Giuffrida et al., 2018). Currently, the jurisprudence regarding the legal and ethical issues of informed consent pertaining to the use of Al is absent, since no case law can be identified in addressing negligence and the use of Al (Solaiman, 2021). Additionally, a point to ponder is whether the present regulations effectively manage the risk or whether they need to be updated to include Al (Giuffrida et al., 2018).

This is not uncommon when a new technology arrives and debate is evident as to whether it can be incorporated into existing theories or whether something new is required (Cohen, 2020). It is also unclear as to how disclosing the use of $\mathrm{Al}$ in making the recommendation will enable a typical patient to better protect his or her own medical interests. Nevertheless, before a decision is required in these cases, a proper information and education about Al decisions should be offered to the patient (Matsuzaki, 2018). It is argued that in obtaining adequate informed consent, there must be a procedure aiding a patient's comprehension of the facts before them, as well as the opportunity for the individual to ask questions (Solaiman, 2021). The complexity of the information that patients will need to assimilate in order to make an informed decision ought to be taken into consideration. However, the disclosure standards are not equipped to address Al's safety leading to the issue of how can we create the reasonable patient in such a way that it satisfies our normative objective of an informed consent doctrine? (Dueno, 2020). The approach to regulating Alenabled products in order to safeguard public safety should be informed by an assessment of the risks that the addition of Al may mitigate, as well as the risks that it may exacerbate (Giuffrida et al., 2018). Additionally, the physician is responsible for ensuring that they are familiar with all the tools they utilise, including an awareness of the risks associated with Al systems (Smith \& Fotheringham, 2020). It can be a daunting undertaking to determine the conduct that resulted in an occurrence which is locked away inside a black box, thus impossible to detect (Giuffrida et al., 2018). The black box nature of an algorithm in this sense, may preclude a physician from taking adequate efforts to mitigate the dangers associated with an Al, yet physicians who utilizes Al may still be compelled to inform or disclose about its use and its limitations, as well as questions about its safety and effectiveness (Smith \& Fotheringham, 2020) (Cohen, 2020). If physicians fail to completely comprehend an Al system's predictions or errors, how may this knowledge gap affect the quality of the informed consent process and, more broadly, medical care?(Cohen, 2020). On another note, even if such disclosure is cost-effective and comprehensive, it is not always desirable for patients to 
be aware of potentially life-threatening dangers, as many feel that "'overdisclosure' undermines patients' ability to distinguish between significant and insignificant threats," making it difficult for patients to discern between them and trivial ones (Cohen, 2020).

\section{Conclusions}

The research has contributed in expanding the requirement of informed consent in light of the use of Al for clinical decision making. This outcome is significant in shaping the transparency and trustworthiness in the governance of Al in healthcare. Such contribution is ultimately in tandem with the Strategic Thrust 2 of the Shared Prosperity Vision 2030 initiated by the Ministry of Economic Affairs in restructuring the priorities of Malaysia's development. This is aimed at revolutionising the healthcare ecosystem through transformative technologies and comprehensive ICT solutions outlined in the Key Economic Growth Activities (KEGA) 14, which includes Al as advanced and modern services. This research addresses on the challenges to mandate disclosure of Al information in healthcare as part of informed consent, as well as the policing of underdisclosure of risks surrounding the deployment of $\mathrm{Al}$ in the medical setting. Future research should further develop and confirm these initial findings by establishing the parameter of which Al's involvement in a patient's health should be disclosed under the current informed consent doctrine. It warrants more discussions and evaluation as to whether the current doctrine is relevant, examining more openly empirical and normative approaches to the question, for instances, by analysing the courts' approach in framing 'adequacy' of information conveyed to patients in medical negligence claims. An operative malpractice liability framework is paramount in providing incentives for policing accurate diagnosis and treatment decisions for patients, all whilst savouring the benefits of disruptive medical technologies.

\section{Acknowledgement}

The authors would like to express their gratitude for the financial support from Universiti Teknologi MARA under the Geran Penyelidikan Khas (600-RMC/GPK 5/3 (265/2020) granted for this research.

\section{References}

Ahmad, M., \& Rohana, A. R. (2016). The Role of Expert Evidence in Medical Negligence Litigation in Malaysia. Pertanika Journal of Social Sciences and Humanities, 24(3), 10571068. http://repo.uum.edu.my

Allain, J. S. (2013). From Jeopardy! To Jaundice: The Medical Liability Implications of Dr. Watson and Other Artificial Intelligence Systems. Louisiana Law Review, 73(4), 10491079.

Amirthalingam, K. (2015). Medical Negligence and Patient Autonomy Bolam Rules in Singapore and Malaysia - Revisited. Singapore Academy of Law Journal, 27(1), 666-693. https://heinonline-org.ezaccess.library.uitm.edu.my

Barfield, W. (2018). Liability for autonomous and artificially intelligent robots. Paladyn, 9(1), 193-203.

Bryden, D., \& Storey, I. (2011). Duty of care and medical negligence. Continuing Education in Anaesthesia, Critical Care and Pain, 11(4), 124-127.

Cohen, I. G. (2020). Informed Consent and Medical Artificial Intelligence: What to Tell the Patient? Georgetown Law Journal 1425., 108(6), 1425-1470.

Council, M. M. (2016). Malaysian Medical Council Guideline: Consent for Treatment of 
Patients by Registered Medical Practitioners. http://www.mmc.gov.my

Dueno, T. (2020). Racist Robots And The Lack Of Legal Remedies In The Use Of Artificial Intelligence In Healthcare. Connecticut Insurance Law Journal, 27(1), 337-358.

Epstein, N. E. (2018). Legal and evidenced-based definitions of standard of care-Implications for code of ethics of professional medical societies.pdf. Surgical Neurology International.

Esham, A. D. B. (2019). The Doctrine of Informed Consent and Duty of Disclosure: A Comparative Essay between the US, UK, Australia and Malaysia with Indonesia. Indonesian Comparative Law Review, 2(1), 13-27.

Giuffrida, I., Lederer, F., \& Vermerys, N. (2018). A Legal Perspective on the Trials and Tribulations of Al: How Artificial Intelligence, the Internet of Things, Smart Contracts, and Other Technologies Will Affect the Law. Case Western Reserve Law Review Volume, 68(3), 748-781.

Griffin, F. (2021). Artificial Intelligence and Liability in Health Care. Health Matrix: Journal of Law-Medicine, 31, 65-106. https://papers.ssrn.com

Jiang, F. (2017). Data Analytics Helps Business Decision Making. Western Oregon University Digital Commons@WOU Student, March, 3-42. https://digitalcommons.wou.edu

Kamensky, S. (2020). Artificial Intelligence and Technology in Health Care: Overview and Possible Legal Implications. DePaul Journal of Health Care Law, 21(3), 1-18. https://heinonline-org.ezaccess.library.uitm.edu.my

Kassim, P. N. J., \& Ibrahim, A. (2002). Medical Negligence Litigation in Malaysia : Current Trend and Proposals for Reform. In Medical Defence Malaysian Berhad. http://mdm.org.my

Kassim, P. N. J., \& Ibrahim, A. (2010). Mediating medical negligence claims in Malaysia : an option for reform. In: Mediation in Malaysia : the law and practice. In IIUM REPOSITORY (IREP) (pp. 321-337). LexisNexis Malaysia Sdn Bhd.

http://www.asiapacificmediationforum.org

Koong, J. K., Rajandram, R., Sidambram, N., \& Narayanan, V. (2021). The effectiveness of handout assisted versus verbal consent on post-operative recall and understanding - $A$ randomized control study. The Surgeon, 1-8.

Mason, C. (1992). Rogers v. Whitaker - Global Health \& Human Rights Database. November. https://www.globalhealthrights.org

Matsuzaki, T. (2018). Ethical Issues of Artificial Intelligence in Medicine. California Western Law Review, 55(1), 255-274.

Pandit, M. S., \& Pandit, S. (2009). Medical negligence: Coverage of the profession, duties, ethics, case law, and enlightened defense - A legal perspective. Indian Journal of Urology, 25(3), 372-378.

Samoili, S., Cobo, L. M., Gómez, E., De Prato, G., Martínez-Plumed, F., \& Delipetrev, B. (2020). Al Watch - Defining Artificial Intelligence. Towards an operational definition and taxonomy of artificial intelligence. In Joint Research Centre (European Commission).

Shabbir, J., \& Anwer, T. (2015). Artificial Intelligence and its Role in Near Future. 14(8), 1-11. http://arxiv.org/abs/1804.01396

Sheet, F. (2015). Hysterectomy Fact Sheet. The National Women's Health Week Network. https://www.nwhn.org

Smith, H., \& Fotheringham, K. (2020). Artificial intelligence in clinical decision-making: Rethinking liability. Medical Law International, 20(2), 131-154. https://doi.org/10.1177/0968533220945766

Solaiman, B. (2021). Addressing Access with Artificial Intelligence: Overcoming the Limitations of Deep Learning to Broaden Remote Care Today. Universty of Memphis Law 
Review, 51(4), 1103-1142. https://heinonline-org.ezaccess.library.uitm.edu.my Vladeck, D. C. (2014). Machines without principals: Liability rules and artificial intelligence. Washington Law Review, 89(1), 117-150. https://digitalcommons.law.uw.edu Wadden, J. J. (2021). What Kind of Artificial Intelligence Should We Want for Use in Healthcare Decision-Making Applications? Canadian Journal of Bioethics, 4(1), 94-100.

Yadav, J., Yadav, M., \& Chand, S. (2020). Medical Negligence and Its determinants. International Journal of Recent Scientific Research, 11(11), 40080-40082. 